\title{
REVISTA DE REVISTAS
}

Eclampsia: tratamiento con veratrum varide, procaina, sulfato de magnesia y dertrosa.

Doctores Alfaro de la Vega, Juirez e Inclán - Gin. y Obs. de Méxien = 1951 . Nímero 2.

Partiendo de la base de que el tratamiento de la eclampsia es sintomatico, los autores utilizaron el conjunto de In terapéntica usual, y a un grupo d. 21 pacientes hicieron el siguiente tratamiento, no sin-observar antes que ese plan no es rigido sino flexible a las circunstancias clinicas y a Ta respuesta:

Hora 0 : 50 e. ce de dextrosa al $50 \%$.

20 a e de sulfato de magnesia al 20\% (enderenesantente)

Hora 0+30: 10 e. e de prosaima al

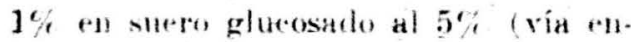
dovenosa lenta y $10 \mathrm{I}$. C. de veratrum viride (vía oral),

I!ora 1 : 20 ces de dextrosa al 50\% y 20 a. e de sulfato de magnesia (vía endovenosa lenta).

Horn 3 :- Como en ta 1.

Horn $6+30$ : Como en la $0+30$.

Hora 7 : Gemo on 1a 1.

Hora $12+30$ - Como en la $0+30$.

Hora 15: Como en in 1.

Hora-18+30: Como en la $0+30$.
Jan resultados-fueron: 20 enfermas euraron del cuadro gestósico; dos tuvieron. como-secuela hipertensión solitaria y una psicosis post-eclámptica. El partó fue en 17 espontáneo y con forceps en 4 ; hubo 2 fetos muertos.

Frocaine fudoecnosn in Ta analgesia di perte.

C. Zaragona Gincria - Gin. y Obs. de Mrives 1951 - Número 3

El rapitulo de lat analgésin obstótrica se enrifueere dia a dín con nuevas experimentaciones $\sin$ gio hastu el presente se llenue al desideratum. Con in enumeracion de sistemas y prosedi. mienter, descie los preentizados en las agoniar del pasalu siglo, hasta los que hey tracen las revistas métions, bien podriamos llenar murhas páginas. El autor, reconociendo piar su técnica no es sino variante de la de Kennetti y Silbert (1947), consistente en inyectar

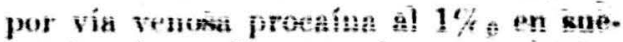
ro fisiologico al $5 \%$, recomienda la misma procuína pero al $1 \%$ en dextrosa a! $5 \%$, al ritno de 25 a 100 gotas por minutr, anotándole como rentajas que

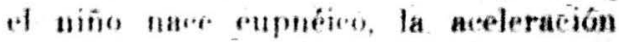
del trabajo, y al ato de les aceddentess convolsivos con sílo retirar de la vewa ba solueión anatgésier. 


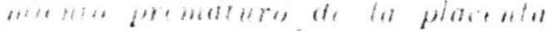

normtinserta.

Alberto Krug Peñafiel - Bul. Soc. Flit. de Obst. y Gin. - 1951 - Nímero 3

El tema del desprendimiento promat turo de la placenta sigue en el orden

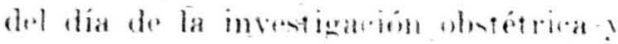

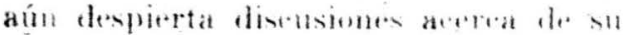
etiologia y terapenties ('orroboramb estudion herbos en nuestra patria, de que ef sindrome anotado no es tan raro como pretenden los que sólo en-él ten= marian in apoplejia uterina de Couvelate, el hutor analiza 300 - asos del Hospitat dr San Franrisen de Borja.

Su anatomopatologia, habida la sirteración de su etiologia gravide toxé. mira, en su major parte. femmintra alteratones de bas fibras masembares "onl disoriarion per anmento de liquide intersticial. dilatarion eapilar y hemorragias interfas-ionlares, forlo lo rual reperente sobre la timimich- uterina.

despecta del tratanionte sin olvidar quare en ocasiones el parta mélies tieue shs exitos enando hay sufreienter indi- la resarta seguida a no de histerectomia seguin el caso. Ello no obstante, la mortalidad materno-fetal sigue muy alta, y de ahi quie deba insistirse en la profilaxia intensificando la atención pre. natul.

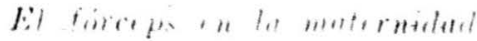

$$
\begin{aligned}
& \text { det Hespelal itntiol. }
\end{aligned}
$$

litr. de Obs if Gim (aratas - 1951. Nimero 3.

El autor de esta trabajo de ingreso a la Soriedad Venezolana de Obstetricia Y. Cinewología, se mestra como poseedor de un alte sintide de autereritica y hater yalat de semsatez y sinceritad. -1 girisa le introita estampa apmello de "quien me se eritina si mismo de un morlo inexorable contimua siende un forpe tocla su vida. porpue no aprende a comocer sus faltas", aseveración que

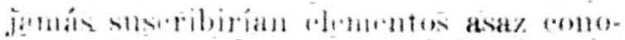
eides y que deberian figurar-en ef сан.

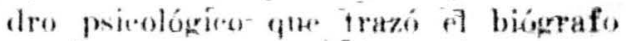
del Emperator Tiberio.

\section{NUEVO TELEFONO DE LA ADMINISTRACION DE FSTA REVISTA}

